\title{
Linfoma cardiaco primario. Presentación de dos casos en pacientes inmunocompetentes
}

\author{
E. MAYAYO ARTAL, R. BALANZÁ ROURE*, L. FONT FERRÉ**, \\ T. ÁLVARO NARANJO* \\ Servicio de Patología. Hospital Universitario de Tarragona Joan XXIII. Servicios de \\ *Patología y **Hematología. Hospital Verge de la Cinta. Tortosa. Tarragona
}

\author{
PRIMARY CARDIAC LYMPHOMA: PRESENTATION OF TWO CASES \\ IN IMMUNOCOMPETENT PATIENTS
}

\section{RESUMEN}

Fundamento: El linfoma cardiaco primario (LCP) es muy infrecuente en pacientes sin alteraciones inmunitarias habiéndose descrito unos 50 casos en el mundo hasta 1996. Su patogenia no se conoce y algunos estudios que han investigado la presencia del virus de Epstein Barr en el tumor en general no lo han demostrado.

Casos: Se describen los casos de dos pacientes con LCP. En ambos casos el diagnóstico fue realizado post mortem.

Ambos pacientes presentaban un linfoma B de células grandes difuso. En los dos casos se ha identificado la presencia de focos inflamatorios a cierta distancia del tumor. No se ha podido demostrar la presencia de VEB en el tumor.

Conclusiones: Los LCPs son tumores de rápido crecimiento con un pronóstico muy desfavorable. El virus de Epstein-Barr no parece desempeñar un papel en la etiopatogenia de estos tumores.

PALABRAS CLAVE: Linfoma. Corazón. Pericarditis. Miocarditis. Virus de Epstein-Barr.

\begin{abstract}
Background: Primary cardiac lymphomas (PCL) are extremely rare in immunocompetent patients. Their pathogenesis seems obscure and a few studies which have sought Epstein Barr virus (EBV) agree that this is generally not demonstrable.

Cases: Two cases of cardiac lymphoma have been described. In both cases, as usually occurs, the histological diagnosis was performed after post-mortem examination.

Histological examinations revealed a B large cell lymphoma in both patients. Autopsy material from both cases showed an imflamatory focus distant from the tumoral mass. EBERs and LMP for EBV were negative.

Conclusions: PCLs are often fast-growing tumours with a highly unfavorable prognosis. Epstein-Barr virus appears to play no role in the development of this malignant condition.
\end{abstract}

KEY WORDS: Lymphoma. Heart. Pericarditis. Myocarditis. EpsteinBarr Virus.

Mayayo Artal E, Balanzá Roure R, Font Ferré L, Álvaro Naranjo T. Linfoma cardiaco primario. Presentación de dos casos en pacientes inmunocom petentes. An Med Interna (Madrid) 2002; 19: 629-631.

\section{INTRODUCCIÓN}

El linfoma cardiaco primario (LCP) es una forma muy infrecuente de presentación de linfoma extranodal (1). Los pacientes suelen presentar insuficiencia cardiaca y derrame pericárdico, y con frecuencia se afectan las cavidades cardiacas derechas. Los métodos más sensibles para diagnosticar este tumor son la resonancia magnética y la ecocardiografía transesofágica . Histológicamente los LCPs son, en la mayoría de casos, linfomas B de células grandes difusos (2). El pronóstico es grave debido a la localización del tumor. El virus de Epstein-Barr (VEB) ha sido descrito como agente causal de LCP en pacientes inmunodeprimidos (3). No obstante no se ha demostrado la relación del VEB como agente causal de LCP en pacientes inmunocompetentes.

En el presente trabajo se describen las características clíni- cas de dos pacientes inmunocompetentes afectos de LCP. Se ha investigado la presencia de VEB en el tumor mediante hibridación in situ e inmunohistoquímica.

\section{CASOS APORTADOS}

Caso 1: Una mujer de 49 años de edad, sin antecedentes patológicos de interés, presentaba un cuadro de dolor en hipocondrio derecho, síndrome tóxico, episodios sincopales y síntomas de insuficiencia cardiaca de dos meses de evolución. El electrocardiograma mostró un bloqueo auriculoventricular de tercer grado que requirió la implantación de un marcapasos externo. El ecocardiograma demostró la presencia de una masa intracardiaca y de líquido en pericardio que tuvo que ser drenado. Fue intervenida quirúrgicamente observándose un tumor que ocupaba las dos cámaras cardiacas derechas y que infiltraba aorta, arterias pulmonares y parte del tabique interven-

Trabajo aceptado: 26 de septiembre de 2001

Correspondencia: L. Font. Servicio de Hematología. Hospital de Tortosa Verge de la Cinta. C/ Esplanetes, 44-58. 43500 Tortosa 
tricular. No fue posible practicar la resección quirúrgica del tumor, falleciendo la paciente durante el postoperatorio inmediato.

El estudio post mortem mostró un linfoma cardiaco primario con afectación cardiaca masiva (ambas auriculas, ventrículo derecho y parte del ventrículo izquierdo, grandes vasos y ganglios mediastínicos supracardiacos).

El estudio histológico demostró un linfoma linfoblástico B con afectación predominante de la superficie pericárdicainfiltrando el miocardio en diversos puntos y avanzando entre los espacios perivasculares. La población celular del tumor estaba constituida por células pequeñas con núcleo redondeado, cromatina granular, sin nucleolo visible, citoplasma escaso, y abundantes mitosis. Se podían observar extensas áreas de necrosis, con aspecto de cielo estrellado, y células tumorales dispuestas en fila india, así como invasión vascular, trombosis, hemorragia intersticial y zonas isquémicas. Se observaron lesiones de pericarditis crónica en el pericardio visceral, no sólo en las zonas adyacentes al tumor sino también en zonas distantes. Además, se observaron focos de fibrosis, con calcificación, infiltrado inflamatorio crónico y aumento de la vascularización (Fig. 1).

El estudio inmunohistoquímico mostró que las células del tumor eran positivas a CD45, CD20, CD79a y BCL-2 y negativas para CD3, CD5, CD10, CD43, cadenas de inmunoglobulinas ligeras y pesadas, CD34 y p53. Los estudios de VEB con inmunohistoquímica (LMP-1) y con hibridación in situ (EBERs) fueron negativos.

Caso 2: Un paciente varón de 68 años de edad, con antecedentes personales de hiperglicemia ocasional fue referido al hospital por presentar disnea, edemas maleolares, algunos episodios nocturnos de dolor retroesternal opresivo de 5 a 10 minutos de duración y síndrome

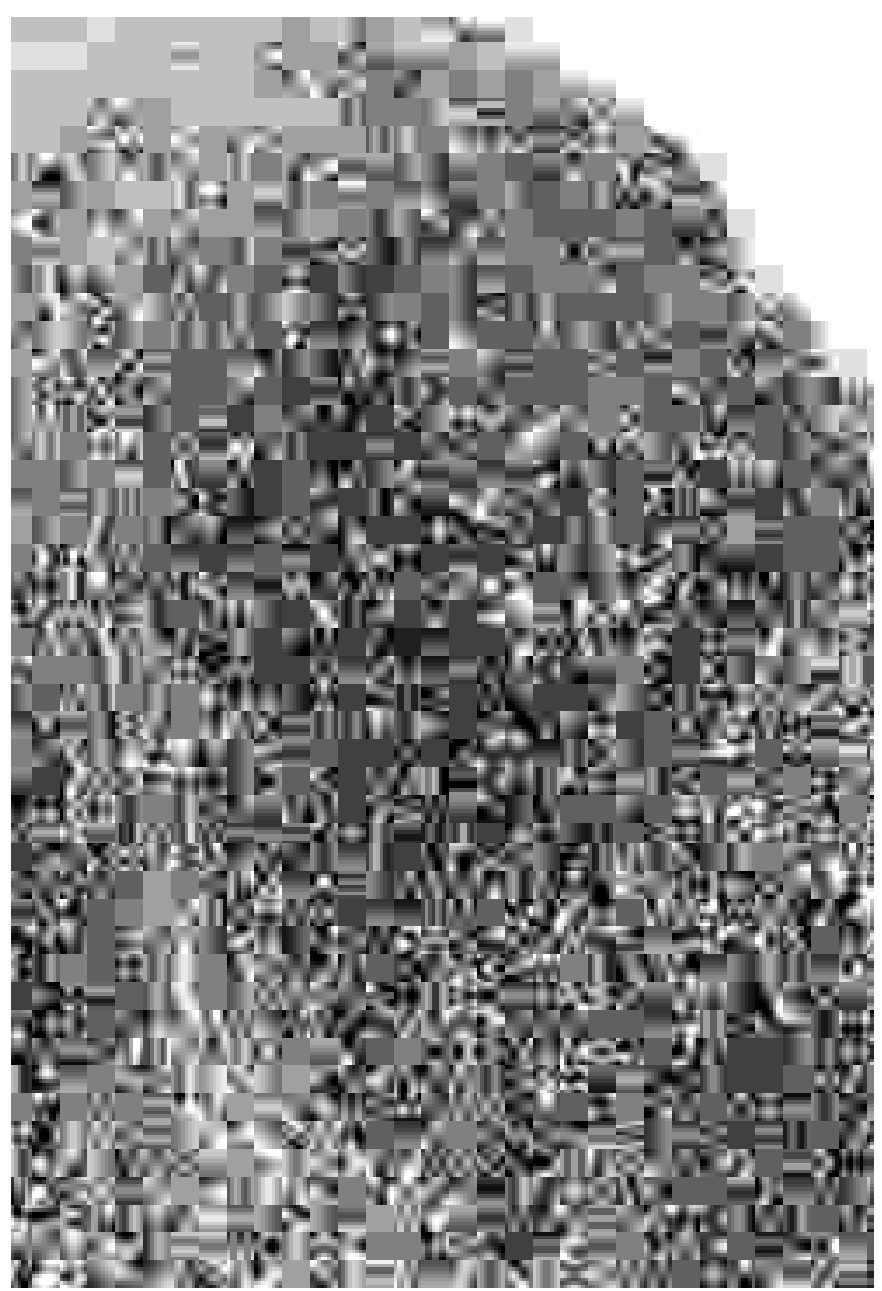

Fig. 1.Linfoma linfoblástico de células $B$ que afecta la superficie del pericardio y muestra una imagen en cielo estrellado. tóxico desde hacía aproximadamente 6 meses. La exploración física mostró un paciente en buen estado general, afebril y no taquipneico. Se evidenció una ingurgitación yugular positiva a 45 grados. La auscultación cardiaca mostraba unos tonos rítmicos, soplo diastólico y clic después del segundo tono. También presentaba hepatomegalia y edemas maleolares. La tensión arterial era de 100/60 mm de Hg.

En el electrocardiograma (ECG) se observó un ritmo nodal a 50 por minuto y un bloqueo de la rama derecha del haz de His. Entre los datos de laboratorio destacaba un aumento de la velocidad de sedimentación globular (VSG) (49 mm por hora) y de la enzima lacticodeshidrogenasa (LDH) (1587 U/L). También presentaba una hiperfibrinogenemia $(6,36 \mathrm{~g} / \mathrm{L})$. El hemograma era normal. La ecocardiografía evidenció la presencia de una masa redonda, de $3,9 \mathrm{~cm}$ de diámetro, adherida a la pared de la aurícula derecha y valva mural de la tricúspide, que dificultaba el llenado del ventrículo derecho, ocasionando un área efectiva de $1 \mathrm{~cm}^{2}$. También se evidenciaron masas en el tabique interauricular así como en la aurícula izquierda. La tomografía axial computadorizada (TAC) torácica y abdominal confirmó los hallazgos cardiacos descritos sin evidenciar adenomegalias ni tumores en otra localización. A los 18 días del ingreso el paciente presentó diversos episodios de fibrilación ventricular, que fueron tratados con desfibrilación, falleciendo finalmente.

El estudio postmortem mostró un corazón con masas subendocárdicas y con infiltración parcial del miocardio subyacente. El estudio histológico mostró un linfoma difuso de células grandes B con células de tamaño heterogéneo, cromatina vesicular, nucleolos únicos o múltiples y citoplasma eosinófilo y plasmacitoide (Fig. 2). Presencia de mitosis abundantes y un alto índice de prolifera-

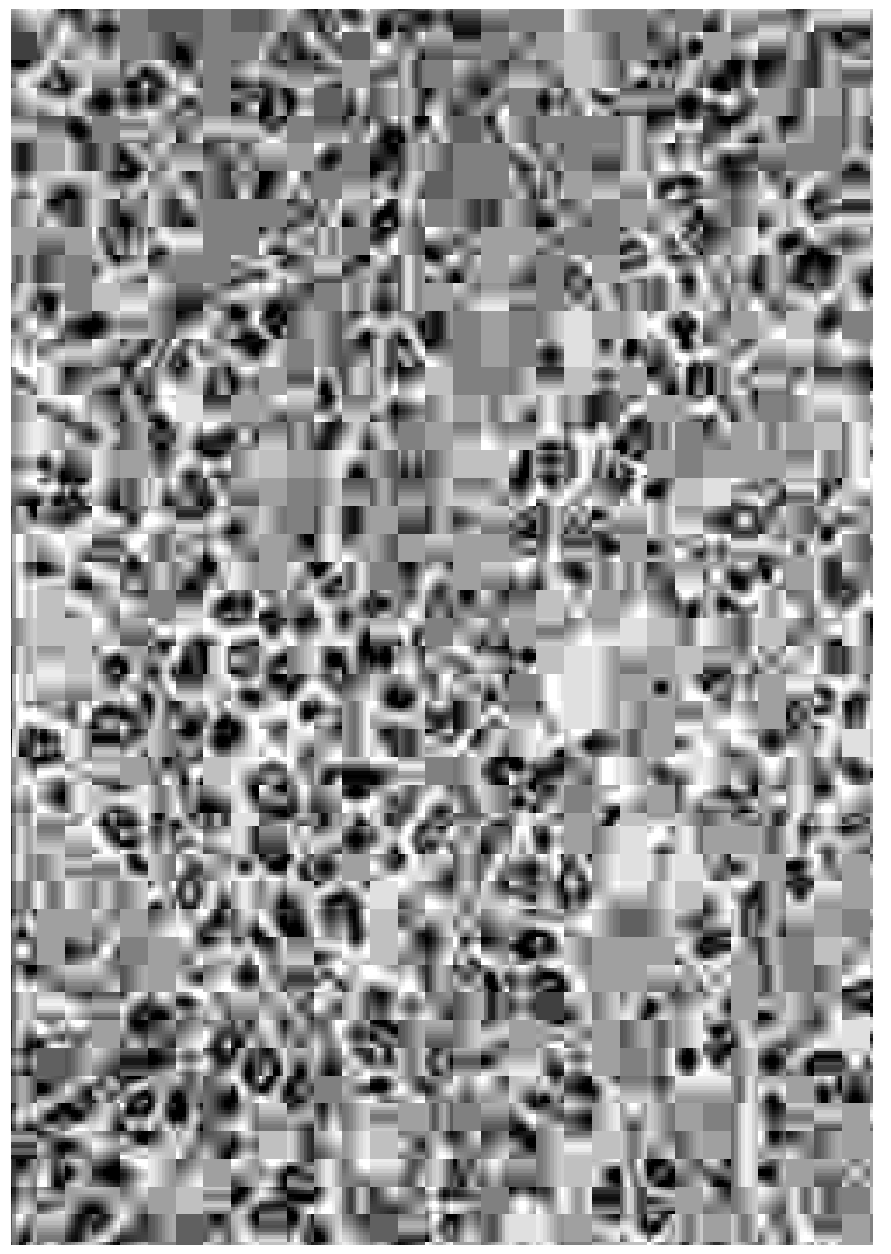

Fig. 2: Linfoma de células B grandes, difuso, con células que contie nen cromatina vesicular, nucleolo prominente y amplio citoplasma, con aspecto plasmacitoide. 
ción (evaluado con el marcador KI-67) en más del 70\% de las células positivas.

El estudio inmunohistoquímico mostró un inmunofenotipo B positivo a CD45, CD20, CD75, CD38 y bcl-2 y secreción IgM lambda. CD43 fue negativo. Había células $\mathrm{T}$ reactivas (positivas para CD3 y CD43) dispersas entre las células tumorales. LMP-1 y EBERs fueron negativos.

Además de la infiltración por el linfoma de la superficie pericárdica fueron observadas extensas bandas de fibrosis y focos inflamatorios. Fue posible identificar áreas de degeneración de fibras miocárdicas a alguna distancia del tumor acompañadas de focos inflamatorios que correspondían a áreas de miocarditis crónica.

\section{DISCUSIÓN}

El linfoma cardiaco primario es una enfermedad muy poco habitual en pacientes inmunocompetentes. Por el contrario, la infiltración cardiaca es un hallazgo no excepcional en pacientes con linfoma diseminado. Para definir un linfoma como primariamente cardiaco debe demostrarse una infiltración exclusiva de tejido cardiaco o de pericardio o, como mínimo, el tumor principal debe localizarse en el corazón aunque pueda encontrarse tumor en otras localizaciones. La afectación cardiaca en el LCP suele ser de cavidades derechas, a diferencia de los mixomas atriales que suelen afectar cavidades izquierdas. Las manifestaciones clínicas del LCP están en relación con las zonas de corazón afectadas: la infiltración masiva de las paredes ventriculares produce insuficiencia cardiaca; las masas atriales derechas dan lugar a obstrucción de la válvula tricúspide y la infiltración septal origina bloqueos auriculoventriculares (4). El pericardio se encuentra frecuentemente afectado y en ocasiones se produce derrame pericárdico (2). Los dos casos descritos en el presente trabajo presentan unas manifestaciones clínicas similares, con dolor opresivo retroesternal, bloqueo de rama derecha del haz de Hiss e insuficiencia cardiaca. Un paciente presentaba derrame pericárdico. En ambos casos, como suele ser habitual en esta enfermedad, el diagnóstico se realizó post mortem (5). El diagnóstico puede realizarse a partir de una citología obtenida por pericardiocentesis guiada por ecocardiografía (sensibilidad del $67 \%)(6,7)$, biopsia intracardiaca transvenosa guiada por ecocardiografia transesofágica (sensibilidad del 100\%) y biopsia cardiaca obtenida por toracotomía (sensibilidad del 100\%). Histológicamente la mayoría de los LCPs publicados son difusos de célula grande B (2). Las posibilidades terapéuticas en los LCPs son limitadas debido a su localización, rápido crecimiento y habitual diagnóstico tardío. La exéresis tumoral generalmente es impracticable debido a la infiltración difusa del tejido cardiaco. La poliquimioterapia ha sido empleada obteniéndose escasas remisiones completas (8-11). No obstante, en algunos casos en que se ha podido establecer un diagnóstico precoz la poliquimioterapia intensiva ha permitido mejorar el pronóstico $(6,7,12)$. En algún paciente se ha realizado quimioterapia intensiva seguida de trasplante de progenitores hematopoyéticos de sangre periférica, con buena respuesta (13).

La relación de diversos agentes etiológicos con la mayoría de linfomas extranodales es un hecho conocido. Dichos agentes producen una estimulación crónica de la inmunidad que causa una proliferación policlonal y finalmente linfoma (14). Helicobacter pylori ha sido implicado en los linfomas gástricos, Borrelia burgdorferi en los linfomas cutaneos, la tiroiditis de Hashimoto en los linfomas de tiroides y la sialoadenitis mioepitelial en los linfomas de la glándula salival. En los linfomas cardiacos se desconoce el mecanismo patogénico. Se ha sugerido el análisis clonal de los infiltrados linfocitarios de los derrames cardiacos para identificar linfomas de bajo grado (5). En nuestros casos el virus de EpsteinBarr no parece estar relacionado con la aparición del LCP, en concordancia con lo descrito previamente (15).

\section{AGRADECIMIENTOS}

Queremos hacer constar nuestro agradecimiento a Maria Teresa Salvadó-Usach, que ha realizado la hibridación in situ para EBER, a Maria del Mar Barberá-Marro, Rosa RisaRollo, Bárbara Tomás, Ana Suñé y Marc Iniesta-Valldepérez por su valioso trabajo técnico y a Anna Carot-Bladé y Rosa Cabrera-Pino por su magnífico trabajo de secretaría.

\section{Bibliografía}

1. García F, Gamallo C, Gil M. Registro Nacional de Tumores Cardiacos (memoria 1996-97). Rev Esp Cardiol 1999; 52: 13-20.

2. Ceseroli GL, Ferreri AJM, Bucci E, Ripa C, Ponzoni M, Villa E. Primary cardiac lymphoma in immunocompetent patients. Diagnostic and therapeutic management. Cancer 1997; 80: 1497-506.

3. Weiss LH, Chang KL. Association of the Epstein-Barr Virus with hematolymphoid neoplasia. Adv Anatomic Pathol 1996; 3: 1-15.

4. Alvarez J, Vivancos R, de Mora M, et al. Linfoma cardiaco primario: presentación de un caso y revisión de la literatura. Rev Esp Cardiol 1997; 50: 444-7.

5. Chim CS, Chan AC, Kwong YL, et al. Primary cardiac lymphoma. Am J Hematol 1997; 54: 79-83.

6. Chao TY, Han SC, Nieh S, et al. Diagnosis of primary cardiac lymphoma. Report of a case with cytologic examination of pericardial fluid and imprints of transvenously biopsied intracardiac tissue. Acta Cytol 1995; 39: 955-9.

7. Castelli MJ, Mihalov ML, Posniak HV, Gatusso P. Primary cardiac lymphoma initially diagnosed by routine cytology. Case report and literature review. Acta Cytol 1989; 33: 355-8.

8. Hwang MH, Brown A, Piao ZE, Scanlon PJ. Cardiac lymphoma associated with superior vena cava syndrome and cardiac tamponade: case

history. Angiology 1990; 41: 328-32

9. Kelsey RC, Saker A, Morgan M. Cardiac lymphoma in a patient with AIDS. Ann Intern Med 1991; 115: 370-1.

10. Roller MB, Manoharan A, Lvoff R. Primary cardiac lymphoma. Acta Haematol (Basel) 1991; 85: 47-8.

11. Aboufalia DM, Bush R, Picozzi VJ. Cardiac tamponade due to primary pericardial lymphoma in a patient with AIDS. Chest 1994; 106: 1295.

12. Pavlidis NA, Elisaf M, Bai M, Tolis C, Papadimitriov C. Primary lymphoma of the pericardium: report of a "cured case" and review of the literature. Med Pediatr Oncol 1994; 22: 287-91.

13. Porcar Ramells C, Clemente González C, García Parés D, Guardia Sánchez R, Pérez Ayuso MJ, García-Bragado Dalmau F. Linfoma cardiaco primario: diagnóstico citológico y tratamiento con respuesta a poliquimioterapia y a autotrasplante de precursores hematopoyéticos. Presentación de un caso y revisión de la literatura. An Med Interna (Madrid) 2002; 19: 305-9.

14. Isaacson PG. Gastrointestinal lymphoma. Hum Pathol 1994; 25: 1020-9.

15. Ito M, Nakagawa A, Tsuzuki T, et al. Primary cardiac lymphoma. No evidence for an etiologic association with Epstein-Barr virus. Arch Pathol Lab Med 1996; 120: 555-9. 